\title{
NILAI TAMBAH DARI USAHA PENGOLAHAN TEPUNG TERIGU MENJADI MARTABAK MARKOBAR KOTA MANADO
}

\author{
Amar \\ Tommy F. Lolowang \\ Nordy F. L. Waney
}

\begin{abstract}
This study aims to determine the magnitude: (1) the added value of flour business into martabak Markobar Manado (2) profit from flour processing business into martabak Markobar Manado City. The study was conducted in October to December 2017, located in Markobar Kota Manado. Data collection method is done by using primary data. Primary data was obtained through interviews with relevant parties based on a prepared list of questions, as well as on-site observations. Data analysis in this study using: 1) value-added analysis and 2) profit analysis with the formula $\pi=T R-T C$. The results showed that Markobar Manado process 3 types of martabak martabak 2 flavors, martabak 4 flavors and martabak 8 flavors. Number of martabak 2 taste processed ie 96 pieces with selling price per fruit of Rp. 50,000 so the total revenue is IDR.4,800,000. Number of martabak 4 flavors processed ie 144 fruit with the selling price per fruit of IDR. 80,000,- so that the revenue received by Markobar is IDR.11,520,000. Number of martabak 8 taste processed ie 240 fruit with selling price per fruit of IDR. 100,000 so that the revenue received by Markobar is IDR.24,000,000. Profit business martabak for 2 taste of IDR. 485,116.71, business profit martabak for 4 taste of IDR. 5,297,675.07 and business profit martabak 8 taste of IDR. 9,322,791.78.- Processing business martabak 2 flavors produce value added IDR 2,357,116.71, processing martabak 4 flavors produce value added IDR. 8,105,675.07,- and martabak processing 8 flavors produce added value of IDR. 14,002,791.78.*eprm*.
\end{abstract}

Keywords: value added, flour processing business, martabak markobar, Manado City

\begin{abstract}
ABSTRAK
Penelitian ini bertujuan untuk mengetahui besarnya: (1) nilai tambah dari usaha pengolahan tepung terigu menjadi martabak (2) keuntungan dari usaha pengolahan tepung terigu menjadi martabak. Penelitian ini di laksanakan pada bulan Oktober sampai Desember 2017, yang berlokasi di Markobar Kota Manado. Metode pengumpulan data dilakukan dengan menggunakan data primer. Data primer diperoleh melalui wawancara dengan pihak bersangkutan berdasarkan daftar pertanyaan yang telah disiapkan, serta pengamatan langsung di lapangan. Analisis data dalam penelitian ini menggunakan: 1) analisis nilai tambah dan 2) analisis keuntungan dengan rumus $\pi=\mathrm{TR}-\mathrm{TC}$. Hasil penelitian menunjukkan bahwa Markobar Manado mengolah 3 jenis martabak yaitu martabak 2 rasa, martabak 4 rasa dan martabak 8 rasa. Jumlah martabak 2 rasa yang diolah yaitu 96 buah dengan harga jual per buah sebesar Rp. 50.000,- sehingga total penerimaan adalah Rp.4.800.000,- Jumlah martabak 4 rasa yang diolah yaitu 144 buah dengan harga jual per buah sebesar Rp. 80.000,- sehingga besar penerimaan yang diperoleh oleh Markobar yaitu Rp.11.520.000,- Jumlah martabak 8 rasa yang diolah yaitu 240 buah dengan harga jual per buah sebesar Rp. 100.000,- sehingga besar penerimaan yang diperoleh oleh Markobar yaitu Rp.24.000.000,- Usaha pengolahan martabak 2 rasa menghasilkan nilai tambah $\mathrm{Rp}$ 2.357.116,71,- pengolahan martabak 4 rasa menghasilkan nilai tambah Rp. 8.105.675,07,- dan pengolahan martabak 8 rasa menghasilkan nilai tambah sebesar Rp. 14.002.791,78,- Keuntungan usaha martabak 2 rasa sebesar Rp. 485.116,71,- keuntungan usaha martabak 4 rasa sebesar Rp. 5.297.675,07,-dan keuntungan usaha martabak 8 rasa sebesar Rp. 9.322.791,78.*prm*.
\end{abstract}

Kata kunci: nilai tambah, usaha pengolahan tepung terigu, martabak markobar, Kota Manado

Agrisosioekonomi:

Jurnal Transdisiplin Pertanian (Budidaya Tanaman, Perkebunan, Kehutanan, Peternakan, Perikanan), Sosial dan Ekonomi 


\section{PENDAHULUAN}

\section{Latar Belakang}

Sektor pertanian mampu memberikan kontribusi yang sangat besar dalam proses pertumbuhan ekonomi negara. Hal ini seiring dengan proses pembangunan dan meningkatnya sektor-sektor yang lain. Sasaran pertumbuhan sektor pertanian tersebut tergolong dalam sasaran pertumbuhan yang cukup tinggi.

Indonesia yang dikenal dengan negara agraris, mampu mengembangkan industri yang maju dan kuat. Dengan demikian, perkembangan agroindustri nantinya tidak hanya ditunjukkan untuk pengembangan kegiatan industri tetapi sekaligus juga dapat mengembangkan kegiatan pengolahan dan pemasaran hasil pertanian.

Pada dasarnya agroindustri merupakan industri yang berbasis pertanian guna menambah nilai dari komoditi pertanian dan menyempurnakan hasil pertanian. Mengingat komoditi pertanian memiliki ciri khas yaitu mudah rusak sehingga perlu untuk dikonsumsi atau diolah terlebih dahulu, maka peran dari agroindustri sangat perlu dilakukan.

Produk pertanian dapat memberi keuntungan dan nilai tambah yang lebih jika produk tersebut diolah melalui berbagai proses produksi. Proses mengubah input menjadi output, yaitu bagaimana mengolah bahan baku menjadi produk sehingga memiliki nilai tambah dankeuntungan. Salah satu produk pertanian yang digunakan sebagai bahan baku industri adalah tepung terigu, yang digunakan untuk membuat berbagai jenis makanan dan kue.

Industri yang sedang dikembangkan dengan bahan baku utama tepung terigu adalah pembuatan martabak. Martabak merupakan makanan yang terbuat dari adonan tepung terigu. Pembuatan martabak dilakukan dengan cara yang sangat sederhana. Martabak juga salah satu makanan manis yang menggoda lidah. Selain itu dengan pilihan berbagai macam rasa tentu akan memanjakan konsumen. Hal ini dikarenakan martabak mempunyai manfaat bagi tubuh dan harga yang relatif dijangkau yang menarik minat masyarakat untuk membelinya.

Martabak saat ini mulai dilirik oleh banyak orang atau wirausaha untuk dikembangkan di Manado. Salah satunya adalah Martabak Kota Barat (Markobar). Usaha Markobar yang berdiri pada tahun 2016 merupakan cabang pertama yang ada di Manado. Saat ini, Markobar sudah beroperasi sekitar satu tahun.

Istilah nilai tambah (added value) itu sendiri sebenarnya menggantikan istilah nilai yang ditambahkan pada suatu produk karena masuknya unsur pengolahan menjadi lebih baik. Adanya industri yang mengubah bentuk primer menjadi produk baru yang lebih tinggi nilai ekonomisnya setelah melalui proses pengolahan, maka akan dapat memberikan nilai tambah karena dikeluarkannya biaya-biaya sehingga terbentuk harga baru yang lebih tinggi dan keuntungannya lebih besar bila di bandingkan tanpa melalui proses pengolahan. Hal tersebut yang mendorong penulis untuk melakukan penelitian sehingga dapat mengetahui lebih lanjut mengenai nilai tambah dari tepung terigu sebagai bahan baku pembuatan martabak pada Markobar.

\section{Bahan Baku Pembuatan Martabak}

Tepung terigu adalah tepung yang terbuat dari biji gandum melalui proses penggilingan. Kata "terigu" sendiri berasal dari bahas Portugis "trigo" yang berarti ganndum. Definisi tepung terigu sebagai bahan makanan menurut SNI (Standard Nasional Indonesia) adalah tepung yang dibuat dari endosperm biji gandum Triticum aestivum L. (Club wheat) atau Triticumcampactum Host atau campuran keduanya dengan penambahan fortifikan zat besi $(\mathrm{Fe})$, seng $(\mathrm{Zn})$, vitamin $\mathrm{B} 1$, vitamin $\mathrm{B} 2$ dan asam folat. Boleh juga ditambahkan BTP (bahan tambahan pangan) yang diizinkan seseuia peraturan BTP.

Tepung terigu merupakan bahan baku utama dalam pembuatan martabak. Bahan baku utama lainnya adalah telur, mentega, soda kue, gula, susu, vanili, wisman, dan air. Seluruh bahan baku utama ini dicampur untuk membuat adonan martabak. Adonan martabak tersebut dimasak sampai matang. Bahan baku penolong yang menjadi topping kemudian ditambahkan untuk menghasikan berbagai jenis rasa martabak (Pricilia et.al., 2014). 


\section{Agroindustri}

Sistem agribisnis terdiri dari empat subsistem yang terkait, yaitu: (a) subsistem rantai produksi, (b) subsistem agroindustri, (c) subsistem institusional atau kelembagaan dan (d) subsistem distribusi dan pemasaran (Gumbira, 2001; Soekartawi, 2000). Subsistem agroindustri merupakan suatu kegiatan ekonomi yang melakukan kegiatan mengubah barang dasar menjadi barang jadi atau setengah jadi dan atau barang yang kurang nilainya menjadibarang yang lebih tinggi nilainya (Aristanto dalam Mokodongan, 2017).

Penggolongan industri oleh menurutbanyaknya tenaga kerja adalah sebagai berikut:

1. Industri rumah tangga, dengan jumlah tenaga kerja 1 sampai 4 orang

2. Industri sedang, dengan jumlah tenaga kerja antara 20 sampai 99 orang

3. Industri kecil, dengan jumlah tenaga kerja antara 5 sampai 19 orang

4. Industri besar, dengan jumlah tenaga kerja 100 orang atau lebih.

Agroindustri merupakan suatu bentuk kegiatan atau aktifitas yang mengolah bahan baku yang berasal dari tanaman maupun hewan (Soekartawi, 2001). Studi agroindustri pada konteks menekankan pada food processing management dalam suatu perusahaan produk olahan yang bahan baku utamanya adalah produk pertanian. Menurut Badan Organisasi PBB yaitu Food and Agriculture Organization (FAO), agroindustri merupakan suatu industry yang mengguna-kan bahan baku pertanian dengan jumlah minimal $20 \%$ dari jumlah bahan baku yang digunakan.

Agroindustri menjadi pusat rantai pertanian yang berperan penting dalam meningkatkan nilai tambah produk pertanian di pasar. Agroindustri meningkatkan devisa negara dengan menjaring nilai tambah, memperkuat struktur ekspor, mengurangi resiko fluktuasi harga komoditas, dan mencegah penurunan nilai tukar, serta antisipasi terhadap kejenuhan pasar komoditas.

Pengembangan agroindustri memiliki beberapa keunggulan karena efek penggandaan dan distribusinya yang besar, komponen impor yang kecil, bertumpu pada sumber daya yang dapat diperbarui, pemicu pertumbuhan daerah baru, dan memperkuat struktur ekspor. Pengembangan agroindustri dapat dimulai dari skala kecil. Industri kecil ini adalah badan usaha yang menjalankan proses produksi untuk menghasilkan barang dan jasa dalam skala kecil. Apabila dilihat dari sifat dan bentuknya, maka industri kecil bercirikan:

(1) berbasis pada sumber daya lokal sehingga dapat memanfaatkan potensi secara maksimal dan memperkuat kemandirian.

(2) dimiliki dan dilaksanakan oleh masyarakat lokal sehingga mampu mengembangkan sumber daya manusia.

(3) menerapkan teknologi lokal (indigenous technology) sehingga dapat dilaksanakan dan dikembangkan oleh tenaga lokal dan.

(4) tersebar dalam jumlah yang banyak sehingga merupakan alat pemerataan pembangunan yang efektif.

\section{Konsep Biaya}

Menurut Sudarman dan Algifari (2001), yang dimaksud dengan biaya adalah semua beban finansial yang harus ditanggung oleh produsen untuk menghasilkan barang atau jasa agara siap digunakan oleh konsumen, baik betul-betul dikeluarkan (explisit cost) maupun yang tidak betul-betul dikeluarkan (implisit cost).

Seperti halnya dengan produksi, biaya yang harus ditanggung produsen dalam suatu kegiatan produksi dapat digabungkan dengan jumlah barang dan jasa yang diproduksi. Dalam suatu fungsi biaya produksi beranggapan bahwa harga input faktor produksi yang digunkan tidak berubah.

Biaya produksi pada suatu kegiatan produksi dibedakan menjadi dua, yaitu:

1. Biaya Tetap (Fixed Cost) adalah biaya untuk faktor produksi tetap. Contoh: biaya sewa, bunga modal, harga mesin dan lainlain.

2. Biaya Variabel (Variable Cost) adalah biaya faktor produksi variabel. Contoh: biaya untuk bahan baku dan tenaga kerja. Biaya Total (TC) adalah biaya tetap total (TFC) ditambah dengan biaya total variabel. Atau secara matematis dapat ditulis sebagai berikut: 
$\mathrm{TC}=\mathrm{TFC}+\mathrm{TVC}$

Keterangan:

TC = Biaya Total (Total Cost)

TFC = Biaya Tetap Total (Fixed Cost)

TVC = Biaya Variabel $($ Variable Cost $)$

\section{Penerimaan}

Penerimaan adalah perkalian antara output yang dihasilkan dengan harga jual (Soekirno,2002; Lipsey et al,1997). Secara sistematis persamaannya dapat ditulis sebagai berikut:

$$
\mathrm{TR}=\mathrm{Q} \times \mathrm{P}
$$

Keterangan:

$\mathrm{TR}=$ Penerimaan total (total revenue)

$\mathrm{Q}=$ Jumlah produk yang dihasilkan (quantity)

$\mathrm{P}=$ Harga (price)

Semakin banyak produk yang dihasilkan maka semakin tinggi harga per unit produk bersangkutan, maka penerimaan total yang diterima produsen akan semakin besar. Sebaliknya jika produk yang dihasilkan sedikit dan harganya rendah maka penerimaan total yang diterima oleh produsen semakin kecil. Penerimaan total yang dikeluarkan akan memperoleh pendapatan bersih yang merupakan keuntungan yang diperoleh produsen.

\section{Rumusan Masalah}

Rumusan masalah dalam penelitian ini adalah berapa besarnya nilai tambah bahan baku dan keuntungan yang diterima pada usaha martabak Markobar Kota Manado.

\section{Tujuan Penelitian}

Untuk menganalisis seberapa besar nilai tambah bahan baku dan menghitungan keuntungan dari usaha martabak pada Markobar berdasdarkan jenis martabak di Kota Manado.

\section{Manfaat Penelitian}

Manfaat penelitian ini adalah memberikan informasi tentang nilai tambah bahan baku dan keuntungan pada usaha martabak Markobar Kota Manado. Penelitian ini diharapkan memberikan kontribusi bagi yang akan melakukan penelitian sesuai, serta dapat menambah wawasan atau pengetahuan mengenai nilai tambah.

\section{METODE PENELITIAN}

\section{Lokasi dan Waktu Penelitian}

Penelitian ini dilakukan selama 3 bulan mulai dari Oktober sampai Desember 2017 pada Markobar yang berlokasi di J1 B. W. Lapian, Tikala, Kota Manado. Usaha ini menjadi salah satu industri pengolahan tepung terigu menjadi martabak.

\section{Metode Pengumpulan Data}

Pengumpulan data meliputi data primer dan data sekunder. Data primer diperoleh melalui wawancara langsung pada pemilik industri martabak dan karyawan (tenaga kerja) serta observasi langsung di tempat penelitian. Data sekunder diperoleh dari berbagai literatur yang berhubungan dengan penelitian ini.

\section{Konsep Pengukuran Variabel}

Dalam penelitian ini variabel yang di ukur adalah :

1. Hasil Produksi, yaitu hasil yang diperoleh dari data produksi bulan November (Rp).

2. Harga Produksi, yaitu harga yang berlaku (Rp).

3. Biaya Tetap, yaitu biaya untuk faktor produksi tetap.

a. Biaya Peralatan (Rp).

b. Biaya Penyusutan Alat, yaitu komponen biaya yang secara tidak langsung dikeluarkan untuk setiap produksi. Biaya penyusutan dihitung dengan formulasi:

$$
\mathrm{P}=\frac{H A-H B}{T}
$$

Keterangan:

$$
\begin{aligned}
& \mathrm{P}=\text { Biaya Penyusutan Alat (Rp) } \\
& \mathrm{HA}=\operatorname{Harga} \text { Awal (Rp) } \\
& \mathrm{HB}=\operatorname{Harga} \text { Akhir (Rp) } \\
& \mathrm{T}=\text { Umur Ekonomis (bulan/tahun) }
\end{aligned}
$$

4. Biaya Variabel, yaitu biaya faktor produksi variabel.

a. Biaya Bahan Baku, yaitu biaya yang dikeluarkan untuk bahan baku yang digunakan ( $\mathrm{Rp} / \mathrm{kg} / \mathrm{hari})$. 
b. Biaya Tenaga Kerja, yaitu biaya yang dibayarkan kepada tenaga kerja (Rp/bulan).

5. Total Biaya, yaitu biaya tetap yang ditambah dengan biaya variabel (Rp).

6. Penerimaan, yaitu perkalian antara output yang dihasilkan dengan harga jual (Rp).

7. Keuntungan, yaitu total penerimaan dikurangi dengan total biaya (Rp).

8. Nilai Tambah Produk Makanan Olahan Tepung Terigu Menjadi Martabak (Rp).

\section{Metode Analisis Data}

Analisis yang digunakan dalam penelitian ini adalah analisis keuntungan yaitu untuk melihat berapa keuntungan dari industri ini menggunakan rumus :

$$
\pi=\mathrm{TR}-\mathrm{TC}
$$

Keterangan:

$\pi \quad=$ Keuntungan usaha (Rp)

$\mathrm{TR}=$ Total Penerimaan $(\mathrm{Rp})$

$\mathrm{TC}=$ Total Biaya $(\mathrm{Rp})$

Untuk biaya total dapat dihitung dengan mengunakan rumus sebagai berikut:

$$
\mathrm{TC}=\mathrm{TFC}+\mathrm{TVC}
$$

Keterangan:

$\mathrm{TC}=$ Total Biaya $(\mathrm{Rp})$

TFC $=$ Total Biaya Tetap $(\mathrm{Rp})$

$\mathrm{TVC}=$ Total Biaya Variabel (Rp)

Untuk menghitung penerimaan dapat dihitung dengan menggunakan rumus sebagai berikut :

Keterangan:

$$
\mathrm{TR}=\mathrm{Q} \times \mathrm{P}
$$

$\mathrm{TR}=$ Total Penerimaan $(\mathrm{Rp})$

$\mathrm{Q}=$ Jumlah Produk

$\mathrm{P}=$ Harga Produk $(\mathrm{Rp})$

Analisis Nilai Tambah untuk menghitung besarnya pertambahan nilai dari martabak, yaitu:

$\mathrm{NTp}=\mathrm{Na}-(\mathrm{Bb}+\mathrm{Bp}+\mathrm{Bbp})$

$$
=\mathrm{Na}-\mathrm{Ba}
$$

Keterangan:

$\mathrm{NTp}=$ Nilai Tambah produk $(\mathrm{Rp}) / \mathrm{kg}$

$\mathrm{Na}=$ Nilai Produk $(\mathrm{Rp})$

$\mathrm{Ba}=$ Biaya antara $(\mathrm{Rp})$

$\mathrm{Bb}=$ Biaya Bahan Baku (Rp)

$\mathrm{Bp}=$ Biaya Penyusutan Alat (Rp)

$\mathrm{Bbp}=$ Biaya Bahan Penolong $(\mathrm{Rp})$
Nilai produk akhir yang dimaksudakan adalah nilai yang diperoleh dari hasil perkalian jumlah output atau total produksi martbak dengan harga jual yang berlaku di pasaran. Dan untuk biaya antara yang dimaksudkan adalah penjumlahan antara biaya bahan baku seperti biaya peralatan, biaya penyusutan alat dan biaya penolong.

Nilai tambah yang dimaksudkan disini adalah perbedaan serta pertambahan nilai suatu produk setelah mengalami proses pengolahan dalam suatu proses produksi. Proses pengolahan nilai tambah produk didefinisikan sebagai selisih anatara nilai produk akhir dengan nilai biaya bahan baku, biaya penyusutan alat dan biaya penolong yang tidak termasuk biaya tenaga kerja.

\section{HASIL DAN PEMBAHASAN}

\section{Deskripsi Tempat Penelitian}

Martabak Kota Barat atau akrab disebut dengan Markorbar merupakan usaha dari menggelar lapak di kawasan kaki lima di Jl. Dr. Moewardi, Solo dekat Lapangan Kota Barat. Markobar pertama kali dibuka pada tahun 2015. Markobar dikembangkan oleh Gibran Rakabuming Raka yang adalah putra sulung dari Joko Widodo. Beliau merupakan presiden Indonesia saat ini. Sebelumnya, Gibran telah mendirikan beberapa usaha seperti catering makanan dan tempat untuk berbagai kegiatan acara.

Usaha martabak Markobar ini tergolong sukses dikarenakan Markobar mempunyai pangsa pasar tersendiri. Mereka adalah anakanak muda penggemar martabak yang bosan dengan topping martabak yang biasa saja. Adapun Markobar tampil beda dengan topping delapan jenis setiap satu pan (loyang/wajan pemanggang). Jadi bila martabak dimakan sebanyak delapan orang, mereka bisa membeli satu martabak dengan delapan varian topping. Martabak satu lingkaran penuh dengan delapan topping yang berbeda, mulai dari cokelat delfi, silver queen, nutela, cadburry, kit kat cokelat, cokelat seres, keju dan oreo. 
Markobar melakukan ekspansi pasar sehingga membuka cabang di Pulau Sulawesi, salah satunya adalah Manado. Markobar cabang Manado dibuka pada Mei 2016 yang beralamatkan di Jl. B. W. Lapian Tikala, Kota Manado. Untuk saat ini, jumlah karyawan yang ada sekitar 3 orang yang mempunyai tugas dan pekerjaan yang berbeda-beda. Markobar Manado dibuka pada pukul 12.00 siang dan ditutup pada pukul 23.00 malam. Terdapat berbagai fasilitas yang tersedia yaitu layanan wifi gratis hingga berbagai alat musik yang tersedia bagi siapapun yang ingin tampil. Pada hari besar keagamaan seperti Natal dan Lebaran, Markobar Manado tidak dibuka atau tidak beroperasi.

Berbagai macam varian topping juga ada di Markobar Manado. Setiap satu jenis topping mempunyai harga sebesar Rp. 80.000. Sedangkan untuk premium, harganya $\mathrm{Rp}$. 100.000. Menurut karyawan, biasanya masyarakat yang menikmati martabak sering menggunakan topping cokelat seres, keju ataupun keduanya dicampur menjadi satu. Markobar Manado juga sudah bekerja sama dengan salah satu layanan online food dalam memasarkan produknya.

\section{Penggunaan Peralatan}

Pengadaan peralatan yang tepat dapat membantu melancarkan proses kegiatan produksi serta dapat memberikan keuntungan bagi usaha martabak. Biaya penggunaan peralatan serta nilai penyusutan setiap alat yang digunakan untuk mengolah tepung terigu menjadi martabak selama proses produksi, dapat dilihat pada Tabel 1 berikut ini:

Tabel 1. Biaya Penyusutan Peralatan Pembuatan Martabak Markobar

\begin{tabular}{lrrr}
\hline \multicolumn{1}{c}{ Nama Alat } & Jumlah & Harga Per Unit & Nilai Penyusutan \\
\hline & & $(\mathrm{Rp})$ & $(\mathrm{Rp} / \mathrm{bulan})$ \\
Kompor & 4 & 450,000 & $24,513.89$ \\
Wajan & 6 & 350,000 & $17,000.00$ \\
Ember & 2 & 25,000 & $2,083.33$ \\
Pisau & 3 & 50,000 & $2,013.89$ \\
Talenan & 1 & 80,000 & $3,333.33$ \\
Mixer & 1 & 180,000 & $14,375.00$ \\
\hline & & Total & $63,319.44$ \\
\hline
\end{tabular}

Sumber: Diolah dari Data Primer, 2017

Tabel 1 menunjukkan jenis dan besarnya biaya penyusutan masing-masing alat untuk produksi. Total biaya penyusutan pada usaha
Markobar sebesar Rp. 63.319,44. Hal ini dikarenakan hampir semua alat digunakan untuk setiap memproduksi martabak. Alat alat tersebut digunakan untuk membuat martabak 2 rasa, 4 rasa dan 8 rasa.

\section{Penyediaan Bahan Baku dan Bahan Penolong}

Bahan baku utama yang digunakan dalam proses pengolahan usaha Markorbar adalah tepung terigu. Bahan baku merupakan bahan mentah yang diolah untuk menghasilkan produk dengan nilai yang lebih tinggi. Ketersediaan bahan baku secara stabil dan berkelanjutan dapat membantu proses produksi suatu perusahaan berrjalan lancar dan perusahaan dapat beroperasi dalam jangku waktu yang lama. Berikut akan dirincikan biaya bahan baku dan bahan penolong dalam proses produksi martabak 2 rasa, 4 rasa dan 8 rasa pada Tabel 2, Tabel 3 dan Tabel 4.

Tabel 2. Biaya Bahan Baku Dan Bahan Penolong Pembuatan Martabak Jenis Dua Rasa Dalam Sebulan

\begin{tabular}{llr}
\hline No & Jenis Bahan & Jumlah Biaya (Rp) \\
\hline & Bahan Baku & \\
\hline 1 & Tepung Terigu & 252.000 \\
2 & Telur & 129.600 \\
3 & Air & 95.999 \\
4 & Soda Kue & 256.000 \\
5 & Gula & 84.000 \\
6 & Vanili & 32.000 \\
7 & Wisman & 34.200 \\
8 & Blue Band & 36.000 \\
\hline & Jumlah & $\mathbf{9 1 9 . 7 9 9}$ \\
\hline & Bahan Penolong & 171.720 \\
\hline 1 & Keju & 38.700 \\
\hline 2 & Seres & $\mathbf{2 1 0 . 4 2 0}$ \\
\hline & Jumlah & $\mathbf{1 . 1 3 0 . 2 1 9}$ \\
\hline & Total
\end{tabular}

Tabel 2 menunjukkan rincian bahan baku dan bahan penolong yang diperlukan dalam proses produksi martabak 2 rasa dalam sebulan. Untuk biaya terbesar ada pada bahan baku utamanya yaitu soda kue sebesar Rp. 219.000 per bulan. Sedangkan biaya terendah atau paling sedikit ada pada vanili sebesar Rp.32.000. Keseluruhan biaya bahan baku dan bahan penolong sebesar Rp. 1.130.219. Sedangkan untuk rincian bahan baku dan bahan penolong yang digunakan dalam proses produksi martabak dalam 1 bulan. 
Tabel 3 menunjukkan rincian bahan baku dan bahan penolong yang diperlukan dalam proses produksi martabak 4 rasa dalam sebulan.

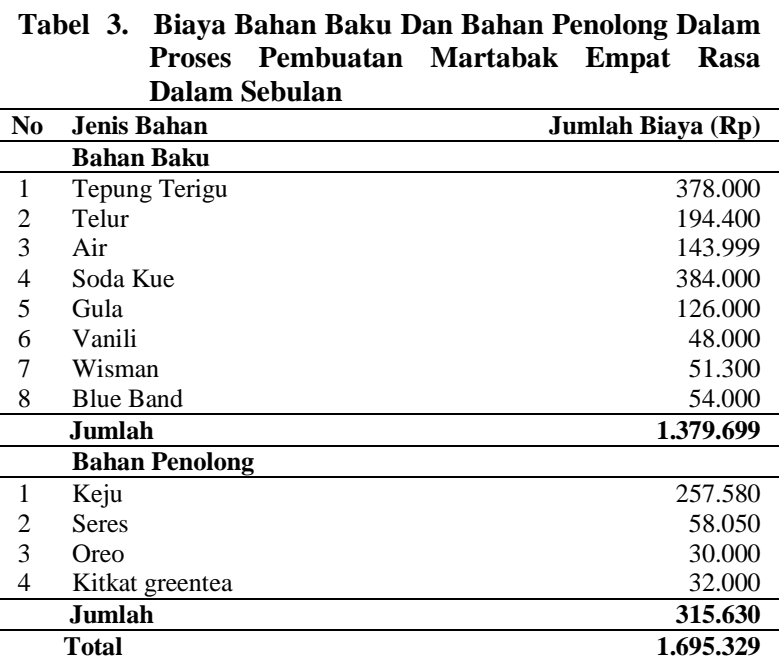

Tabel 3 menunjukkan rincian bahan baku dan bahan penolong yang diperlukan dalam proses produksi martabak 4 rasa dalam sebulan. Untuk biaya terbesar ada pada bahan baku utamanya yaitu soda kue sebesar Rp. 384.000 per bulan. Sedangkan biaya terendah atau paling sedikit ada pada oreo sebesar Rp.30.000. Keseluruhan biaya bahan baku dan bahan penolong sebesar Rp. 1.695.329. Sedangkan untuk rincian bahan baku dan bahan penolong yang digunakan dalam proses produksi martabak dalam 1 bulan.

Tabel 4 menunjukkan rincian bahan baku dan bahan penolong yang diperlukan dalam proses produksi martabak 8 rasa dalam sebulan.

\begin{tabular}{|c|c|c|}
\hline No & Jenis Bahan & Jumlah Biaya (Rp) \\
\hline & \multicolumn{2}{|l|}{ Bahan Baku } \\
\hline 1 & Tepung Terigu & 630.000 \\
\hline 2 & Telur & 324.000 \\
\hline 3 & Air & 239.999 \\
\hline 4 & Soda Kue & 640.000 \\
\hline 5 & Gula & 210.000 \\
\hline 6 & Vanili & 80.000 \\
\hline 7 & Wisman & 85.500 \\
\hline \multirow[t]{3}{*}{8} & Blue Band & 90.000 \\
\hline & Jumlah & 2.299 .499 \\
\hline & \multicolumn{2}{|l|}{ Bahan Penolong } \\
\hline 1 & Keju & 429.300 \\
\hline 2 & Seres & 96.750 \\
\hline 3 & Nutella & 360.000 \\
\hline 4 & Kitkat & 360.000 \\
\hline 5 & Dairy milk & 1.120 .000 \\
\hline 6 & Toblerone & 1.040 .000 \\
\hline 7 & Silver Queen & 760.000 \\
\hline 8 & Delfi & 1.000 .000 \\
\hline & Jumlah & \begin{tabular}{|l|l|}
5.166 .050 \\
\end{tabular} \\
\hline & Total & 7.465 .549 \\
\hline
\end{tabular}

Tabel 4 menunjukkan rincian bahan baku dan bahan penolong yang diperlukan dalam proses produksi martabak 8 rasa dalam sebulan. Untuk biaya terbesar ada pada bahan baku utamanya yaitu soda kue sebesar Rp. 640.000 per bulan. Sedangkan biaya terendah atau paling sedikit ada pada vanili sebesar Rp.80.000 Keseluruhan biaya bahan baku dan bahan penolong sebesar Rp. 7.465.549. Rincian bahan baku dan bahan penolong yang digunakan dalam proses produksi martabak dalam 1 bulan.

\section{Biaya Produksi}

Biaya yang tergolong dalam biaya tetap adalah biaya penyusutan alat yang digunakan dalam proses produksi, biaya listrik setiap bulannya, biaya sewa tempat setiap bulannya dan pajak yang dikenakan pada usaha Markobar Cabang Manado. Sedangkan biaya variabel terdiri dari biaya bahan baku, biaya bahan penolong dan biaya tenaga kerja setiap bulannya.

Tabel 5. Biaya Pengolahan Martabak Dua Rasa Pada

\begin{tabular}{llr}
\multicolumn{3}{c}{ Markobar Dalam 1 Bulan } \\
\hline No. & \multicolumn{1}{c}{ Uraian } & Jumlah (Rp) \\
\hline 1. & Biaya Tetap & $12.663,89$ \\
& 1. Biaya Penyusutan & \\
& Peralatan & $200.000,00$ \\
2. Biaya Listrik/Gas & $500.000,00$ \\
3. Biaya Sewa Tempat & $600.000,00$ \\
\hline 4. Pajak & $919.799,40$ \\
Biaya Variabel & $210,420.00$ \\
\hline & a. Biaya Bahan Baku \\
b. Biaya Bahan Penolong & $1.872 .000,00$ \\
c. Biaya Tenaga Kerja & $\mathbf{4 , 3 1 4 , 8 8 3 . 2 9}$ \\
\hline & Total Biaya
\end{tabular}

Tabel 5 menunjukkan bahwa biaya tetap yang ada dalam proses produksi martabak sebesar Rp. 1.312.663,89 dan biaya variabelnya sebesar Rp. 3.002.219,40

dengan perincian yaitu biaya bahan baku, biaya bahan penolong dan biaya tenaga kerja. Pada Markobar, jumlah tenaga kerja sebanyak 3 orang dengan upah sbesar Rp.120.000 per hari. Untuk biaya total dapat dihitung dengan mengunakan rumus sebagai berikut:

$$
\begin{aligned}
\text { TC } & =\quad \text { TFC + TVC } \\
& =\text { Rp. } 1.312 .663,89+\text { Rp. } 3.002 .219,40 \\
& =\text { Rp. } 4.314 .883,29
\end{aligned}
$$


Tabel 6 menunjukkan bahwa biaya tetap yang ada dalam proses produksi martabak sebesar Rp. 1.718.995,83 dan biaya variabelnya sebesar Rp. 4.503.329,10 dengan perincian yaitu biaya bahan baku, biaya bahan penolong dan biaya tenaga kerja. Pada Markobar, jumlah tenaga kerja sebanyak 3 orang dengan upah sbesar Rp.120.000 per hari. Untuk biaya total dapat dihitung dengan mengunakan rumus sebagai berikut:

$$
\begin{aligned}
\mathrm{TC} & =\mathrm{TFC}+\mathrm{TVC} \\
& =\text { Rp. } 1.718 .995,83+\text { Rp. } 4.503 \cdot 329,10 \\
& =\text { Rp. } 6.222 .324,93
\end{aligned}
$$

Tabel 7. Biaya Pengolahan Martabak Delapan Rasa Pada Markobar Dalam 1 Bulan

\begin{tabular}{llr}
\hline No. & \multicolumn{1}{c}{ Uraian } & Jumlah (Rp) \\
\hline 1. & Biaya Tetap & \\
& 1. $\quad$ Biaya Penyusutan & $31.659,72$ \\
& $\quad$ Peralatan & \\
& 2. $\quad$ Biaya Listrik/Gas & $500.000,00$ \\
& 3. Biaya Sewa Tempat & $500.000,00$ \\
& 4. Pajak & $1.500 .000,00$ \\
\hline 2. & Biaya Variabel & $2.299 .498,50$ \\
\hline & d. Biaya Bahan Baku & $5,166,050.00$ \\
& e. Biaya Bahan Penolong & $4.680 .000,00$ \\
\hline & f. Biaya Tenaga Kerja & $\mathbf{1 4 . 6 7 7 . 2 0 8 , 2 2}$ \\
\hline & Total Biaya & \\
\hline
\end{tabular}

Sumber : Diolah dari data primer, 2017

Tabel 7 menunjukkan bahwa biaya tetap yang ada dalam proses produksi martabak sebesar Rp. 2.531.659,72 dan biaya variabelnya sebesar Rp. 12.145.548,50 dengan perincian yaitu biaya bahan baku, biaya bahan penolong dan biaya tenaga kerja. Pada Markobar, jumlah tenaga kerja sebanyak 3 orang dengan upah sebesar Rp.120.000 per hari. Untuk biaya total dapat dihitung dengan mengunakan rumus sebagai berikut:

$\mathrm{TC}=\mathrm{TFC}+\mathrm{TVC}$

$$
\begin{aligned}
& =\text { Rp. } 2 \cdot 531 \cdot 659,72+\text { Rp. } 12 \cdot 145 \cdot 548,50 \\
& =\text { Rp. } 14 \cdot 677 \cdot 208,22
\end{aligned}
$$

\section{a. Penerimaan Usaha}

Jumlah penerimaan usaha pengolahan tepung terigu pada usaha Markobar diperoleh dari perkalian antara harga jual martabak dengan jumlah martabak yang diolah. Jumlah martabak 2 rasa, 4 rasa dan 8 rasa yang diproduksi untuk 1 bulan telah dirincikan dalam Tabel 8.
Tabel 8. Penerimaan Usaha Pembuatan Martabak Markobar Menurut Jenis Martabak Dalam 1 bulan

\begin{tabular}{ccrr}
\hline $\begin{array}{c}\text { Jenis } \\
\text { Martabak }\end{array}$ & $\begin{array}{c}\text { Jumlah yang } \\
\text { Diproduksi (buah) }\end{array}$ & Harga (Rp) & Total (Rp) \\
\hline 2 rasa & 96 & 50.0000 & 4.800 .000 \\
4 rasa & 144 & 80.0000 & 11.520 .000 \\
8 rasa & 240 & 100.0000 & 24.000 .000 \\
\hline \multicolumn{4}{c}{} \\
\hline
\end{tabular}

Sumber : Data diolah dari data primer, 2017

Penerimaan usaha yang diperoleh dari martabak 2 rasa, 4 rasa dan 8 rasa masing masing sebesar Rp. 4.800.000, Rp. 11.520.000 dan Rp. 24.000.000.

\section{b. Analisis Nilai Tambah}

Perhitungan nilai tambah usaha martabak pada Markobar dilakukan untuk mengetahui besarnya nilai yang ditambahkan pada bahan baku utama.

Perhitungan Analisis Nilai Tambah untuk Martabak 2 rasa:

$$
\begin{aligned}
\mathrm{NTp} & =\mathrm{Na}-(\mathrm{Bb}+\mathrm{Bp}+\mathrm{Bbp}) \\
& =\mathrm{Na}-\mathrm{Ba} \\
& =4.800 .000-(919.799,40+1.312 .663 .89+210.420) \\
& =4.800 .000-2.442 .883 .29 \\
& =2.357 .116 .71
\end{aligned}
$$

Berdasarkan perhitungan tersebut, maka nilai tambah untuk martabak 2 rasa yang diperoleh dari usaha ini adalah sebesar Rp. 2.357.116.71.

Perhitungan Analisis Nilai Tambah untuk Martabak 4 rasa:

$$
\begin{aligned}
\mathrm{NTp} & =\mathrm{Na}-(\mathrm{Bb}+\mathrm{Bp}+\mathrm{Bbp}) \\
& =\mathrm{Na}-\mathrm{Ba} \\
& =11.520 .000-(1.379 .669,10+1.718 .995 .83+315.630,00) \\
& =11.520 .000-3.414 .324,93 \\
& =8.105 .675,07
\end{aligned}
$$

Berdasarkan perhitungan tersebut, maka nilai tambah untuk martabak 4 rasa yang diperoleh dari usaha ini adalah sebesar Rp. 8.105.675,07.

Perhitungan Analisis Nilai Tambah untuk Martabak 8 rasa:

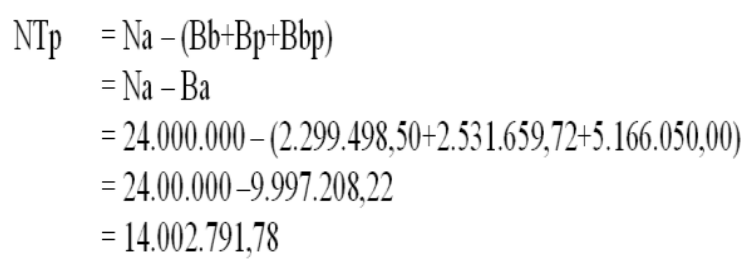


Berdasarkan perhitungan tersebut, maka nilai tambah untuk martabak 8 rasa yang diperoleh dari usaha ini adalah sebesar Rp. 14.002.791,78.

\section{c. Keuntungan Usaha}

Tujuan dari suatu perusahaan adalah memperoleh keuntungan yang besar dan selalu berkelanjutan. Sehingga keuntungan yang diperoleh dari usaha pengolahan tepung terigu menjadi martabak adalah selisih antara total penerimaan dengan total biaya yang ada dalam usaha ini. Besarnya keuntungan yang dapat diperoleh Markorbar dalam sebulan untuk jenis 2 rasa, 4 rasa dan 8 rasa.

Total biaya yang digunakan untuk martabak 2 rasa adalah sebesar $\mathrm{Rp}$. 4,314,883.29 dengan menggunakan bahan baku utama tepung terigu sebanyak $24 \mathrm{~kg}$ menghasilkan 96 buah martabak.

Keuntungan yang diperoleh dari martabak 2 rasa yaitu :

$$
\begin{aligned}
\pi & =\mathrm{TR}-\mathrm{TC} \\
& =\text { Rp. } 4.800 .000-\mathrm{Rp} 4,314,883.29 \\
& =\text { Rp. } 485,116.71
\end{aligned}
$$

Usaha martabak 2 rasa Markobar memperoleh penerimaan kotor sebesar Rp. 4.800.000, setelah dikurangi biayabiaya maka keuntungan bersih yang diperoleh adalah Rp. 485,116.71

Total biaya yang digunakan untuk martabak 4 rasa adalah sebesar Rp. 6.222.324,90 dengan menggunakan bahan baku utama tepung terigu sebanyak $36 \mathrm{~kg}$ menghasilkan 144 buah martabak.

Keuntungan yang diperoleh dari martabak 4 rasa yaitu :

$$
\begin{aligned}
\pi & =\mathrm{TR}-\mathrm{TC} \\
& =\text { Rp. } 11.520 .000-\mathrm{Rp} 6.222 .324,93 \\
& =\text { Rp. 5.297.675,07 }
\end{aligned}
$$

Usaha martabak 4 rasa Markobar memperoleh penerimaan kotor sebesar Rp. 11.520.000, setelah dikurangi biayabiaya maka keuntungan bersih yang diperoleh adalah Rp. 5.297.675,07. Total biaya yang digunakan untuk martabak 8 rasa adalah sebesar Rp. 14.677.208,22 dengan menggunakan bahan baku utama tepung terigu sebanyak $48 \quad \mathrm{~kg}$ menghasilkan 240 buah martabak. Keuntungan yang diperoleh dari martabak 4 rasa yaitu:

$$
\begin{aligned}
\pi & =\mathrm{TR}-\mathrm{TC} \\
& =\mathrm{Rp} .24 .000 .000-\mathrm{Rp} 14.677 .208,22 \\
& =\text { Rp. 9.322.791,78 }
\end{aligned}
$$

Usaha martabak 8 rasa Markobar memperoleh penerimaan kotor sebesar Rp. 11.520.000, setelah dikurangi biaya-biaya maka keuntungan bersih yang diperoleh adalah Rp. 9.322.791,78.

\section{KESIMPULAN DAN SARAN}

\section{Kesimpulan}

Berdasarkan hasil penelitian yang telah dilakukan pada Markobar Manado yang mengolah tepung terigu menjadi martabak disimpukan bahwa:

1. Usaha pengolahan martabak 2 rasa menghasilkan nilai tambah $\mathrm{Rp}$ 2.357.116,71,- pengolahan martabak 4 rasa menghasilkan nilai tambah $\mathrm{Rp}$. 8.105.675,07,- dan pengolahan martabak 8 rasa menghasilkan nilai tambah sebesar Rp. 14.002.791,78,-

2. Keuntungan usaha martabak 2 rasa sebesar Rp. 485.116,71,- keuntungan usaha martabak 4 rasa sebesar Rp. 5.297.675,07,dan keuntungan usaha martabak 8 rasa sebesar Rp. 9.322.791,78.-

\section{Saran}

Perlu adanya dukungan dari Pemerintah baik dari sisi kemampuan finansial maupun kemampuan manajerial pada usaha pengolahan makanan berbahan terigu lainnya agar dapat meningkatkan nilai tambah produk tersebut.

\section{DAFTAR PUSTAKA}

Gumbira dan Intan. 2001. Manajemen Agribisnis. Ghalia Indonesia. Jakarta. 
Lipsey, R, et.al. 1997. Pengantar Mikroekonomi. Binarupa Aksara. Jakarta.

Mokodongan, W. 2017. Analisis Nilai Tambah Agroindustri Rumah Tangga Produk Keripik Pisang (Studi Kasus Kecamatan Malalayang). Skripsi Fakultas Pertanian Universitas Sam Ratulangi. Manado.
Soekartawi. 2000. Agribisnis: Teori dan Aplikasinya. PT. Raja Grafindo Persada. Jakarta.

Soekartawi. 2001. Pengantar Agroindustri. PT. Raja Grafindo Persada. Jakarta.

Sudarman, A dan Algifari. 2001. Ekonomi Mikro-Makro: Teori, Soal dan Jawaban. BPFE-UGM. Yogyakarta. 